\title{
Development and Field Testing of a Real-Time PCR Assay for Caprine Arthritis-Encephalitis-Virus (CAEV)
}

\author{
Giovanni Brajon ${ }^{*}, 1$, Daniela Mandas ${ }^{2}$, Manuele Liciardi ${ }^{4}$, Flavia Taccori ${ }^{1}$, Mauro Meloni ${ }^{2}$, \\ Franco Corrias ${ }^{1}$, Caterina Montaldo ${ }^{5}$, Ferdinando Coghe $^{2}$, Cristina Casciari ${ }^{3}$, \\ Monica Giammarioli ${ }^{3}$ and Germano Orrù ${ }^{* 2,5}$
}

\author{
${ }^{1}$ Istituto Zooprofilattico Sperimentale delle Regioni Lazio e Toscana, Sezione di Firenze, Firenze, Italy \\ ${ }^{2} D N A$ Sequencing Service (DSS), AOU, Cagliari, Italy \\ ${ }^{3}$ Istituto Zooprofilattico Sperimentale dell'Umbria e delle Marche, Perugia, Italy \\ ${ }^{4}$ Istituto Zooprofilattico Sperimentale della Sardegna, Dipartimento di Cagliari, Cagliari, Italy \\ ${ }^{5}$ OBL, Diparimento di Scienze Chirurgiche, Università di Cagliari, Cagliari, Italy
}

\begin{abstract}
Caprine arthritis/encephalitis (CAE) of goats and occasionally sheep are persistent virus infections caused by a lentivirus (CAEV). This viral infection results in arthritis in adult animals and encephalitis in kids. Prognosis for the encephalitic form is normally poor, with substantial economic loss for the farm. In this context an early/fast laboratory diagnosis for CAEV infection could be useful for effective prophylactic action. In this work we performed a quantitative real time PCR designed on the CAEV env gene to detect/quantify in goat/sheep samples, viral RNA or proviral DNA forms of CAEV. This procedure was validated in 15 sheep, experimentally infected with CAEV or with a highly correlated lentivirus (visna maedi, MVV); in addition, a total of 37 clinical goat specimens recruited in CAEV positive herds were analyzed and compared using serological analysis (Elisa and AGID). All samples infected with MVV resulted negative. In sheep experimentally infected with CAEV, proviral DNA was detectable 15 days post infection, whereas the serological methods revealed an indicative positivity after 40-60 days. This method showed a sensitivity of $10^{2}$ env fragments/PCR) with a linear dynamic range of quantitation from $10^{3}$ to $10^{7}$ env fragments/PCR; the R2 correlation coefficient was 0.98. All subjects with a clinical diagnosis for Caprine Arthritis-Encephalitis (CAE) resulted CAEV DNA positive.
\end{abstract}

Keywords: Caprine arthritis-encephalitis, CAEV, lentivirus, real time PCR, agar gel immunodiffusion (AGID), enzyme-linked immunosorbent assay (ELISA).

\section{INTRODUCTION}

Among the group of small ruminant lentiviruses (SRLV), Caprine arthritis-encephalitis virus (CAEV) is able to infect goats and occasionally sheep and other related ruminants [1, 2]. The major transmission route of this virus is through the ingestion of virus-infected milk from adult goats by kids via colostrum, by iatrogenic transmission or by lateral transmission through prolonged close contact, with infected animals. All breeds and ages of goats are susceptible to infection, and once established, it persists throughout the animal's life. CAEV infection of goats in newborn kids may lead to encephalitis, interstitial pneumonia and in adult animals to chronic arthritis and interstitial mastitis, and all may contribute to impaired milk production [3]. Infection with CAEV has been identified worldwide [4-8]. CAEV has a tropism for monocytes and macrophages; the infection of

*Address correspondence to these authors at the DSS. Università degli Studi di Cagliari, Via Binaghi 4, 09121 Cagliari, Italy; Tel: 0039070 537413; Fax: 0039070 537437; E-mail: orru@unica.it and Istituto Zooprofilattico Sperimentale delle Regioni Lazio e Toscana. Sezione di Firenze, Via Castelpulci 43, 50018 Scandicci, Italy; Tel: 0039055 721308; Fax: 0039055 7311323; E-mail: giovanni.brajon@izslt.it host cells involved in the immune system carries the virus throughout the body with multi organ involvement and progression to the disease can take months to years, causing chronic inflammatory diseases. CAEV is closely related to the maedi-visna virus (MVV), but it is a genetically distinct lentivirus. As nucleotide sequence information has increased, it has been shown that MVV and CAEV should not be regarded as sheep-specific and goat-specific pathogens respectively, but rather that they should be more correctly referred to as SRLV [1, 9, 10]. In the diagnostic field, serological tests are routinely applied to detect SRLV infections. Although third-generation ELISAs, like those used in this study, are highly sensitive and specific [11], seroconversion can, however, be relatively slow and variable and there is no simple relationship between the moment of conversion and the initial infection. To be able to prove the availability of actual viral particles in blood and tissues, a PCR test may be used, as in the present study. Theoretically, SRLV can be present in the clinical samples (blood, organs, semen) in three forms: namely (i) incorporated proviral DNA (in macrophages), (ii) as virions (complete virus particles with their ssRNA core and protein coat released by budding from the plasma membrane) and (iii) as free virus (released 
by cell lysis). In practice, CAEV proviral-DNA and viral mRNA could be detected by PCR base methods. The current most widely used test for caprine arthritis-encephalitis (CAE) is agar gel immunodiffusion (AGID) recommended by the World Animal Health Organization (OIE,2009). However, this seems to underestimate infection incidence especially in animals with delayed sera conversion [12]. This can impede early or precise serological diagnosis in animals, which could be an efficient infection source. By direct diagnostic procedures, CAEV-DNA or CAEV-RNA have been detected by PCR or RT-PCR base methods, these procedures required identification by agarose electrophoresis or sometimes by the capillary sequencing method [13-15]. Up until now, these molecular tools have required a long time and can be expensive; in addition, they do not allow viral quantization; to overcome these problems, we used a real time PCR method for the detection and quantization of CAEV strains in different goat clinical samples. This could be a useful anti-CAEV prophylactic strategy controller or used in experimental infection studies for monitoring, avoiding possible cross reactions with other strongly related virus such as maedi visna virus (MVV). The purpose of this study was to develop a real-time PCR assay able to detect/quantify CAEV DNA or RNA in goat/sheep clinical samples.

\section{MATERIALS AND METHODOLOGY}

\section{Animals and Clinical Samples}

Our studies were performed in two distinct Italian native goat populations: (I) Sardinian, (II) Alpine, Central Italy.

A total of thirty-seven goat samples were processed:

Sardinian goat population, 16 subjects from 2 herds, ten of these were culled (Table 1).

- $\quad 16$ DNA extracts from blood

- $\quad 10$ DNA extracts from intra-articular fluid

Table 1. PCR Real Time Results Relative to Samples Recruited from Sardinian Goats (Istituto Zooprofilattico Sperimentale Della Sardegna)

\begin{tabular}{|c|c|c|c|c|c|}
\hline $\mathbf{N}$ & Sample & Organ & Sintomatology & AGID & PCR Real Time \\
\hline 1 & K88 & BLOOD & PRESENT & POSITIVE & POSITIVE \\
\hline 2 & K199 & BLOOD & ABSENT & NEGATIVE & NEGATIVE \\
\hline 3 & K163 & BLOOD & ABSENT & POSITIVE & POSITIVE \\
\hline 5 & K134 & BLOOD & PRESENT & POSITIVE & POSITIVE \\
\hline 5 & K134 & IAF & PRESENT & POSITIVE & NEGATIVE \\
\hline 6 & K133 & BLOOD & ABSENT & NEGATIVE & POSITIVE \\
\hline 7 & K120 & BLOOD & PRESENT & POSITIVE & POSITIVE \\
\hline 9 & $\mathrm{G} 02$ & BLOOD & ABSENT & POSITIVE & POSITIVE \\
\hline 9 & G02 & IAF & ABSENT & POSITIVE & NEGATIVE \\
\hline 10 & A29 & BLOOD & ABSENT & POSITIVE & POSITIVE \\
\hline 10 & A29 & IAF & ABSENT & POSITIVE & NEGATIVE \\
\hline 11 & A23 & BLOOD & PRESENT & POSITIVE & POSITIVE \\
\hline 11 & $\mathrm{~A} 23$ & IAF & PRESENT & POSITIVE & NEGATIVE \\
\hline 12 & $\mathrm{~A} 02$ & BLOOD & ABSENT & POSITIVE & NEGATIVE \\
\hline 12 & $\mathrm{~A} 02$ & IAF & ABSENT & POSITIVE & NEGATIVE \\
\hline 16 & 213835 & IAF & PRESENT & POSITIVE & NEGATIVE \\
\hline
\end{tabular}


- $\quad 10$ RNA extracts from intra-articular fluid

Clinical evaluation for CAEV symptoms was observed for these subjects [16].

Alpine goat population, 21 subjects from 1 herd

- 21 DNA extracts from blood

- $\quad 21$ RNA extracts from serum

These herds occasionally showed serological CAEV positivity by the Agar Gel Immuno diffusion (AGID) technique [17], or by ELISA [18] see Tables 1 and 2.

In addition, 15 other sheep, serologically negative for CAEV and recruited from a herd from central Italy, were used for CAEV/MMV experimental infections (see later).

\section{Viral Strains}

Two different viral clinical isolates (CAEV and MMV) were used for sheep experimental infection and as positive controls, in order to check the reliability of the real time PCR procedure described in this paper.

1. The first strain, originally isolated by explantation of the synovial membrane from an arthritic goat, (It-Pi1) was identified as a CAEV- like genotype B by traditional PCR procedures [19, 20].
2. The second Visna maedi- like strain (It-651), obtained by sheep tissue explantation, was identified as genotype A $[20,21]$.

\section{Serological Analysis}

Serological analysis was performed by the Agar Gel Immuno diffusion (AGID) technique and by Elisa procedures described by other authors in previous publications $[17,20]$. In particular, two commercially available ELISAs were used. One whole virus ELISA (hereafter named WVcomELISA) was from Bommeli Diagnostics (Checkit MVV/CAEV) and a recombinant based ELISA (named RcomELISA) was made by the Institut Pourquier, employing the recombinant capsid antigen and trans membrane protein. Both tests were carried out following the manufacturer's instructions.

\section{Experimental Infection}

Experimental infection was carried out during a previous study at Perugia's Istituto Zooprofilattico Sperimentale (IZSP) and a set of immunological results with some samples has already been published, Lacerenza et al., 2006 [20].

Briefly, 15 sheep from the Appennine population were selected from a long term negative flock and housed in

Table 2. PCR Real Time Results Relative to Samples Recruited from Alpine Goats (Istituto Zooprofilattico sperimentale delle Regioni Lazio e Toscana)

\begin{tabular}{|c|c|c|c|c|}
\hline $\mathbf{N}^{\circ}$ & Sample & Elisa & Real Time PCR Blood & $\begin{array}{c}\text { RT-Real Time PCR } \\
\text { Serum }\end{array}$ \\
\hline 1 & 433 & Negative & Positive & Negative \\
\hline 2 & 364 & Negative & Negative & Negative \\
\hline 3 & 429 & Negative & Negative & Negative \\
\hline 4 & 439 & Negative & Negative & Negative \\
\hline 6 & 435 & Negative & Negative & Negative \\
\hline 7 & 334 & Negative & Negative & Negative \\
\hline 8 & 347 & Negative & Negative & Negative \\
\hline 9 & $\mathrm{CL}$ & Positive & Positive & Negative \\
\hline 12 & 420 & Positive & Positive & Negative \\
\hline 13 & 373 & Positive & Positive & Negative \\
\hline 14 & 413 & Positive & Positive & Positive \\
\hline 15 & 414 & Positive & Positive & Positive \\
\hline 16 & 402 & Positive & Positive & Positive \\
\hline 17 & 401 & Positive & Positive & Positive \\
\hline 18 & 351 & Positive & Positive & Positive \\
\hline 19 & 353 & Positive & Negative & Positive \\
\hline
\end{tabular}


Perugia's Istituto Zooprofilattico Sperimentale at the age of 8 months. They were kept here for another 6 months before experimental infection and tested twice with negative results for small ruminant lentivirus antibodies. On the day before infection, the subjects were randomly divided into three groups (five sheep per group) each housed in different independent units:

- $\quad$ Group A were uninfected (negative control, receiving $1 \mathrm{ml}$ of mock, consisting of uninfected cell culture medium).

- $\quad$ Group B were infected by intratracheal administration of $1 \mathrm{ml}$ of virus, containing cell culture supernatant (strain It- It-Pi1, $4.6 * 10^{3}$ TCID50/ml, CAEV).

- $\quad$ Group C were infected by intratracheal administration of $1 \mathrm{ml}$ of virus, containing cell culture supernatant (strain It- 561, 4.6*10 $10^{3}$ TCID50/ml) (MVV).
All sheep were sampled before inoculation on the day of infection, and at regular intervals (every 7 days) until day 71 . Serum and blood samples were collected for serological analysis and nucleic acid extraction. Use of these samples was authorized by IZSP.

\section{Viral nucleic Acid Extraction}

DNeasy 96 Blood \& Tissue Kit (QIAGEN) was used for DNA extraction from blood and intra-articular fluid. RNeasy Mini Kit (QIAGEN) was used for RNA extraction from sera, while QiAamp RNA Blood Mini Kit was used for RNA extraction from fresh whole blood. For a correct procedure we followed the manufacturer's instructions. The concentration of nucleic acid nucleic suspensions was measured with a Qubit ${ }^{\circledR}$ 2.0 Fluorometer by using a Qubit ${ }^{\circledR}$ RNA Assay Kit and Qubit ${ }^{\circledR}$ dsDNA HS Assay Kit (Invitrogen) following the manufacturer's instructions for RNA and DNA measurement respectively. These samples were stored at $-80^{\circ} \mathrm{C}$ until use.

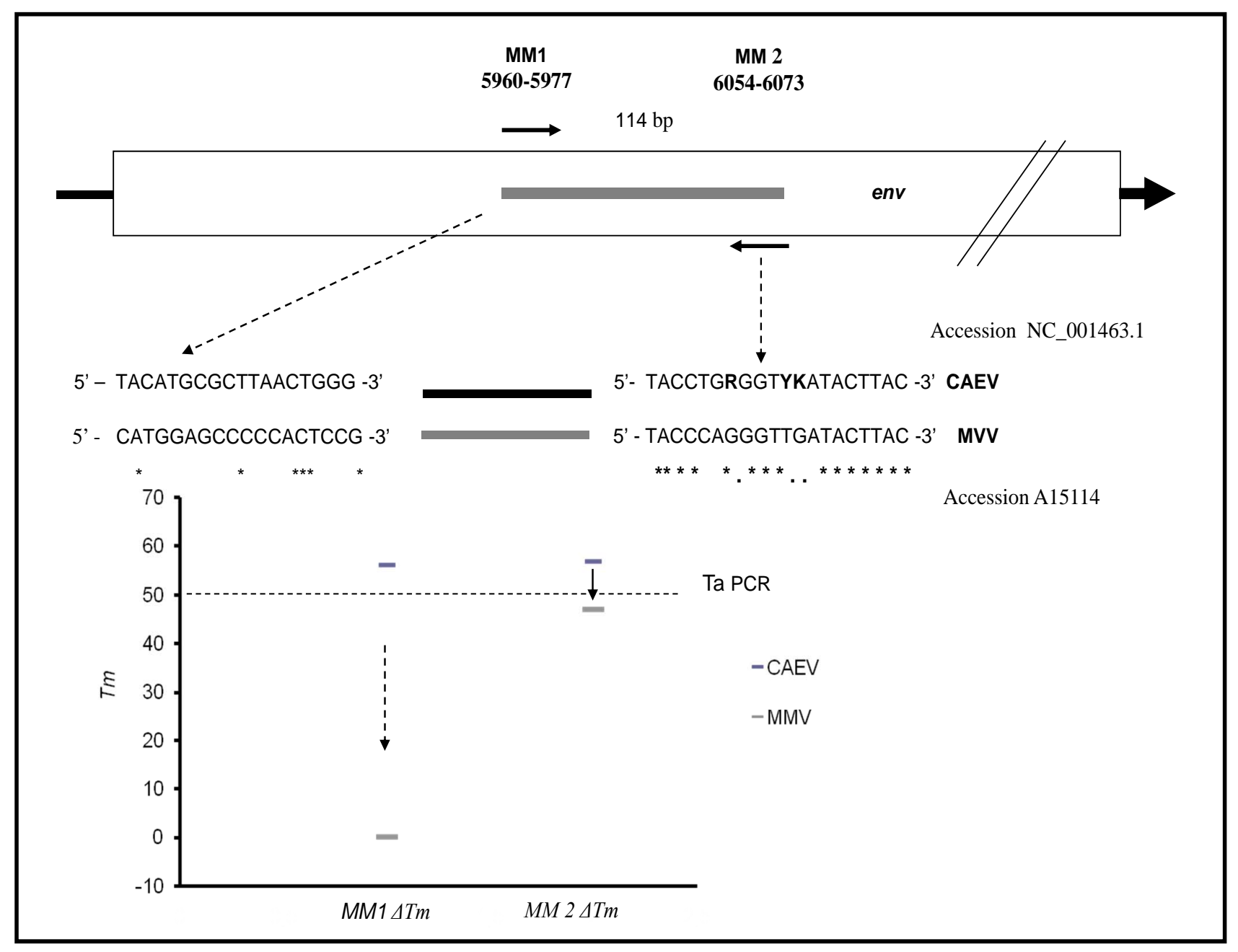

Fig. (1). Sequences and positions of primers employed in this work ; in comparison with the corresponding MVV -env region, PCR primers MM1 and MM2 designed for CAEV detection/quantification showed a discrete number of mismatches. The presence of the asterisk represents a perfect nucleotide identity between shown sequences. The point represents a degenerate region (identities for some genotypes only). The MM2 downstream oligonucleotides presented degenerate sequences, in bold the nucleotide. Thus, when these oligos are thermodynamically compared with the target MMV gene region, they showed a melting temperature $\mathrm{Tm} 7-50^{\circ} \mathrm{C}$ in decrease, even though the downstream oligos (MM2) show from 3 to 7 nucleotides in identities in the 3' region (see graph). These in silico results suggest an uncrossed reaction between CAEV/MMV genotypes during PCR reaction. 


\section{Oligonucleotide Primers Design}

The PCR target region was identified by multiple sequence alignment programs (ClustalW, and Geneious Biomatters Ltd.) by means of the complete CAEV and visna Maedi proviral genomes, available in the DNA data Bank (GenBank). The env gene sequences, codifying for CAEV viral envelope polyprotein, showed a good conserved region inside the CAEV group, even though a mean difference was observed with the Visna Maedi virus (Fig. 1). The PCR primers, used to perform real time PCR, were designed from a $114 \mathrm{bp}$ fragment, corresponding to nucleotide positions from 5960 to 6073 in the published CAEV genome sequence identified with GenBank accession n. NC_001463. The theoretical melting temperatures of the primers $\left(T m_{s}\right)$, the formation of oligonucleotide dimers and selfcomplementarity were evaluated using Oligo Program version 4 (MedProbe, Oslo, Norway) and by module 1 of the DNA Hybridisation prediction algorithm program, HYTHER http://ozone.chem.wayne.edu/ [22, 23]. Parameters set as hybridisation conditions were a monovalent cation concentration of $0.05 \mathrm{~mol} / \mathrm{L}, \mathrm{Mg} 2+$ at $0.004 \mathrm{~mol} / \mathrm{L}$, a concentration of probe and target of $10^{-7} \mathrm{~mol} / \mathrm{L}$ and a hybridisation temperature of $50^{\circ} \mathrm{C}$. This fragment was chosen for its high similarity in all CAEV genotypes. The positions of the PCR primers and the comparative matches with the visna maedi (MVV) env region are shown in Fig. (1).

\section{Positive Quantitative Standard}

A synthetic 114 bp DNA fragment (MM4) was used as a positive control. This fragment, corresponding to the PCR amplicon was synthesized by eurofins MWG/operon (www.eurofinsdna.com). Serial 10 fold dilutions of this target, ranging from $10^{6}$ molecules $/ 2 \mu 1$, served as a standard quantification curve.

\section{Optimal Amounts of Template DNA for PCR Reaction}

Proviral CAEV DNA is normally represented as the smallest percentage in the sample compared to goat eukaryotic DNA. This aspect could compromise PCR reaction as a false negative result [24]. The clinical sample analyzed in this study showed a total DNA concentration ranging from 5 to $43 \mathrm{ug} / \mathrm{ml}$. For this reason, we performed a real time PCR reaction containing a serial dilution of mixed goat DNA, from 50 to $0.78 \mu \mathrm{g} / \mathrm{ml}$, with a synthetic CAEV target MM4 env molecules/PCR at a concentration of $1 * 10^{5}$ (Table 1). The DNA amount was calculated by a Qubit ${ }^{\circledR} 2.0$ Fluorometer (Invitrogen) following the manufacturer's instructions.

\section{Real Time RT-PCR}

In this work we used a version 1.2 LightCycler Instrument, (Roche Diagnostics Mannheim, Germany).

\section{Real Time RT-PCR for CAEV RNA}

PCR was performed with a LightCycler-RNA Amplification kit SYBR Green I (Roche Diagnostics Mannheim Germany) according to the manufacturer's instructions. The $20 \mu$ final volume contained: $2.5 \mathrm{mM} \mathrm{MgCl} 2,0,5 \mu \mathrm{M}$ of each primer and $1 \mathrm{U}$ of heat-labile Uracyl-DNA-Glicosilase (UDG, Roche Molecular Biochemicals), $2 \mu 1$ of RNA extract. The PCR program was as follows: (i) an initial reverse transcription at $55^{\circ} \mathrm{C}$ for $10 \mathrm{~min}$. (ii) denaturation at $95^{\circ} \mathrm{C}$ for $30 \mathrm{sec}$. and (iii) 40 cycles of $0 \mathrm{sec}$ at $95^{\circ} \mathrm{C}, 10 \mathrm{sec}$ at $50{ }^{\circ} \mathrm{C}$, $24 \mathrm{sec}$ at $72^{\circ} \mathrm{C}$ and $3 \mathrm{sec}$ at $79{ }^{\circ} \mathrm{C}$ (vi) Melting curve: performed for 0 seconds at $95^{\circ} \mathrm{C}, 45^{\circ} \mathrm{C}, 95^{\circ} \mathrm{C}$. Transition rates were: $5{ }^{\circ} \mathrm{C} / \mathrm{s}$ in $72^{\circ} \mathrm{C}$ segment, $0.1{ }^{\circ} \mathrm{C} / \mathrm{s}$ in $45^{\circ} \mathrm{C}$ segment and $20^{\circ} \mathrm{C} / \mathrm{s}$ for another step. Fluorescence was detected at the end of the $79^{\circ} \mathrm{C}$ segment in the PCR step (single mode) and at the $45^{\circ} \mathrm{C}$ segment in the melting step (continuous mode) in the F1 channel.

\section{Real Time PCR for CAEV Proviral DNA}

PCR was performed with a LightCycler-DNA Amplification kit SYBR Green I (Roche Diagnostics Mannheim Germany) according to the manufacturer's instructions. The $20 \mu \mathrm{l}$ final volume contained: $2.5 \mathrm{mM}$ $\mathrm{MgCl} 2,0,5 \mu \mathrm{M}$ of each primer, $2 \mu \mathrm{l}$ of DNA extract. The PCR program was the same as described above without the reverse transcription step. The quantitative real time PCR or real time RT-PCR, performed with the LightCycler (Roche Diagnostics Mannheim, Germany), required 30 minutes.

\section{RESULTS}

\section{Magnesium Optimization}

Magnesium concentration is a critical factor affecting the performance of Taq DNA polymerase. PCR reaction components can affect the amount of free magnesium. In the absence of adequate magnesium, Taq DNA polymerase is ineffective. On the contrary, excess free magnesium reduces enzyme fidelity and may increase the level of nonspecific amplification [24]. For this reason, we prepared a reaction series containing 3-5.5 mM, $\mathrm{Mg}^{2+}$ in $0.4 \mathrm{mM}$ increments by adding 0-0.4-0.8-1,2-1.6-2 $\mu \mathrm{l}$ of a $25 \mathrm{mM} \mathrm{MgCl}_{2}$ stock to 20 $\mu 1$ reactions as described in the "LightCycler ${ }^{\circledR}$ DNA/RNA SYBR Green I" Kit instruction manuals. The most sensitive combination was observed with $\mathrm{MgCl}_{2} 3.5 \mathrm{mM}$, with a shift in the PCR threshold cycle (CT) from 32 to 12.

\section{Melting Curve and Procedure Specificity}

The melting temperature of a DNA duplex, with SYBR green dye, gives information about DNA fragment length [25], which shows dissociation-characteristics of doublestranded DNA during heating and, normally we can observe two different melting peaks after real time PCR reaction: the first low temperature melting peak represents a possible primer-dimer PCR product; the second (at a higher temperature), represents the signal corresponding to PCR amplicon dissociation. Thus a negative result is represented with the first peak only. RT-PCR, generation of melting curves and fluorescence detection were all performed using: (i) viral strains, (ii) positive clinical strains for MMV and CAEV, (iii) $\mathrm{CAEV} / \mathrm{MMV}$ negative goat samples. As described in Fig. (2), a $82^{\circ} \mathrm{C}$ melting Peak is shown in CAEV samples, even though a $\mathrm{T}_{\mathrm{m}}$ peak shift $\left(82-76^{\circ} \mathrm{C}\right)$ was detected in the case of MMV samples or in the negative control. These results confirm the prediction obtained by an in silico study described in Fig. (1).

\section{Sensitivity}

Real-time PCR, as evaluated here, has been shown to have a detection limit of $10^{2}$ synthetic MM4 fragment/PCR. The wide linear range $\left(10^{7}-10^{3} \mathrm{MM} 4 / \mathrm{PCR}\right)$ as illustrated in 
Fig. (3), Standard curves showed a good correlation regression coefficient R2 of 0.98 [26].

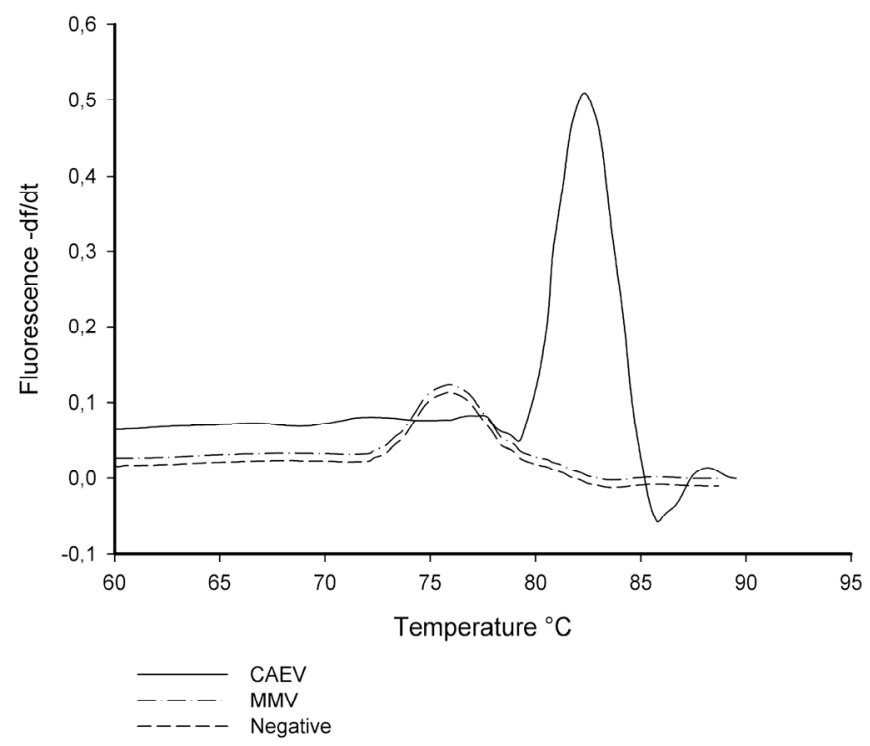

Fig. (2). Real time PCR melting curve in CAEV and MMV samples. Only the positive CAEV samples showed a Melting curve peak profile of $83^{\circ} \mathrm{C}$.

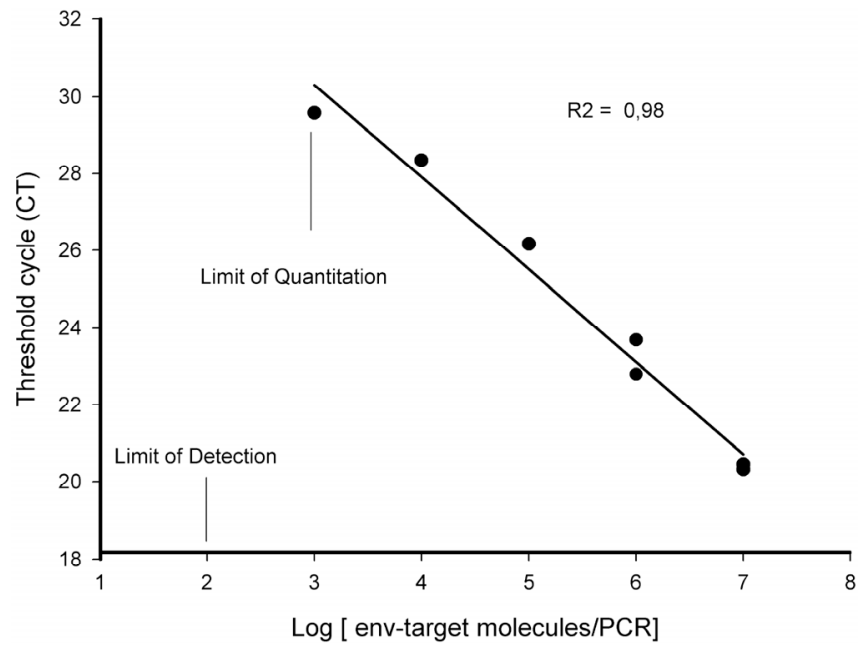

Fig. (3). Real time PCR standard curve obtained with serial dilution of synthetic MM4 CAEV target. The linear range of quantitation was $10^{3}-10^{7}$ molecules/PCR. All CAEV positive samples showed a concentration ranging under quantification limit $10^{2} \leq 10^{3}$ envmolecules/PCR, the detection limit was $10^{2}$ env- molecules/PCR.

\section{Optimal Amount of Total DNA Concentration}

The PCR reaction was performable at all serial dilutions of goat DNA tested. Early CT values were around 18 and they were observed under $12.5 \mu \mathrm{g} / \mathrm{ml}$ of total DNA, corresponding to the samples diluted $1 / 4$ fold, (data not shown).

\section{Infected Sheep}

As described in the Materials and Methods section: a cohort of three different groups of sheep were used, with 5 subjects each of which were :

infected with a CAEV strain (It-Pi1), (iii) non- infected.

For serological analysis and nucleic acid extraction, we took serum and blood specimens for each sheep at 4 , $8,15,23,28,42,58,71$ days after infection. Real time PCR and RT-real time PCR showed that:

MMV infected and non infected sheep resulted PCR negative (data not shown).

Viral RNA in all infected sheep was undetectable by RT real time PCR (data not shown).

As shown in Fig. (4a), proviral DNA was detectable in blood, 15 days after infection for all CAEV infected sheep. The titres (the mean for 5 sheep, calculated as a MM4 CAEV fragment/PCR) ranged from $9 * 10^{2}\left(15^{\text {th }}\right.$ day PI) to $1 * 10^{4}$ $\left(71^{\text {th }}\right.$ day PI). $1 * 10^{3}$ fragment/PCR, corresponding to about $5 * 10^{4}$ virus particles $/ \mathrm{ml}$ blood.

Fig. (4b) represents the percentage of positivity of CAEV antigens obtained with two different Elisa manufacturer's kits (Bommelli and Pourquier). Significant positivity (> $50 \%$ ) was detected after 60 days PI. The Bommelli kit resulted positive around 20 days PI but it showed a lower positivity percentage $(<20 \%)$.

\section{Clinical Samples}

A total of thirty seven goat samples were processed. All positive specimens analyzed showed a very low viral titre ( $\leq$ 103 C env-DNA copies $/ \mathrm{ml}$ ).

\section{Sardinian Goats}

We analyzed a total of 16 subjects from 2 herds. All symptomatic goats (5/16 subjects) and 6 asymptomatic subjects resulted Blood DNA CAEV positive (Table 1), no intrarticular fluid (IAF) resulted positive for CAEV DNA or RNA.

\section{Central Italy Goats (Alpine).}

Of the 21 goats analyzed, Table $\mathbf{2}$, only two samples showed a discrepancy between the serological (Pourquier) and molecular analysis. Sample n. 1 resulted CAEV DNA positive but serologically negative, while sample n. 21 was Elisa positive with CAEV DNA/RNA negative. Considering only the Elisa positive specimens, $77 \%$ were Blood CAEV DNA positive and $53 \%$ were serum RNA positive. Real time PCR (DNA+RNA) revealed $92 \%$ serological positive samples (12/13) CAEV positive and 25\% Elisa negative samples.

\section{DISCUSSION AND CONCLUSION}

Caprine arthritis-encephalitis (CAE) is a disease in goats and sheep caused by a retrovirus (CAEV). This is a persistent lentivirus infection and is often grouped with the Maedi visna (MVV) virus which is a small ruminant lentivirus, SRLV [27]. It is an emerging problem throughout Europe, particularly in the Mediterranean regions. The disease tends to spread widely if left uncontrolled and most affected animals are culled because these animals are sources of infection and their clinical signs worsen over time, causing high economic loss. At the present time, there are no biological products such as vaccines for CAEV prophylaxis; in fact, the only choice is infection prevention by early 

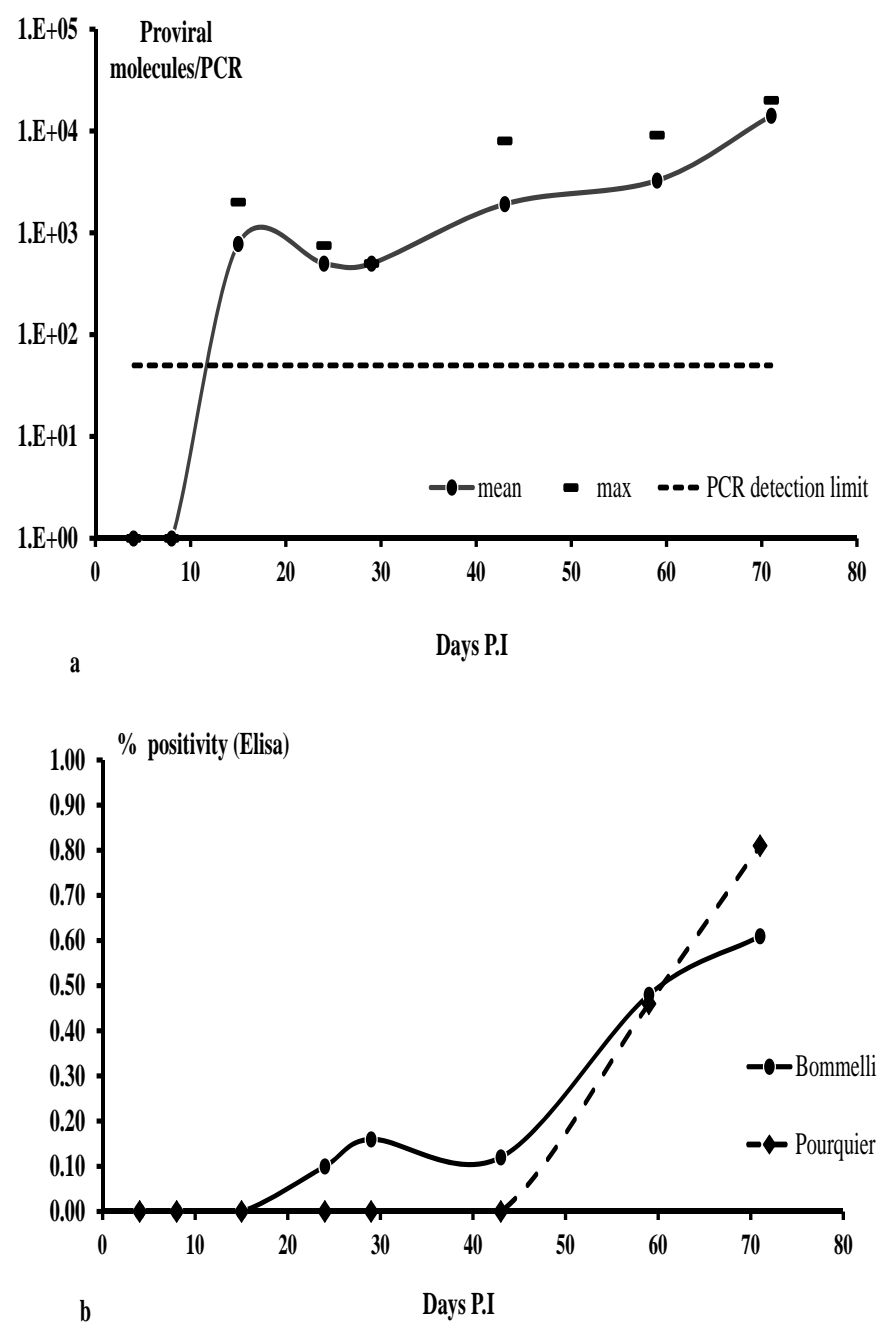

Fig. (4). (a) Titre of proviral CAEV DNA measured in infected sheep at 71 days post infection. The represented titre was the geometrical mean in five subjects. (b) Serological Elisa results for the same specimens are described in figure.

identification and isolation of CAEV-infected subjects. Most infected subjects possess detectable specific antibodies and a number of serological test are available for CAEV infection diagnosis. The two most commonly used are the agar gel immuno diffusion test (AGID) and the enzyme-linked immunosorbent assay, ELISA [11, 28]. In a previous work, Adams et al. [29] demonstrated that Virus-inoculated goats produced a CAEV- specific antibody that reached a maximum level between 49 and 77 days post inoculation. In this work, we also observed that a significant positivity $(>50 \%)$ could be detected after around 60 days PI in infected sheep. Following other literature data, the time required for seroconversion following infection can be relatively prolonged and unpredictable, measured in months rather than in weeks [17, 30-32]; this "window period" could cause prevention strategies to fail with a subsequent spread of infection. Direct virus isolation by co-cultivating peripheral blood or milk leukocytes with appropriate caprine cell cultures, such as synovial membrane cell isolation and subsequent confirmation by immunolabelling and electron microscopy is very specific but showed variable sensitivities
[33]; in addition, this method requires specialised laboratories.

Direct laboratory diagnosis by CAEV nucleic acid recognition for detecting CAEV virus or provirus has already been described [6, 13-15, 34-40]. These procedures represent in situ hybridization methods or PCR (polymerase chain reaction) methods. PCR base methods are now routinely being used in different laboratories, and their specificity is confirmed by amplicons or cloning products.

Traditional PCR is inexpensive, easy to use but current molecular methods do not allow simultaneous CAEV detection/quantization. We have described a fast molecular procedure (around 1.5-2 hours) with good sensitivity and specificity, able to detect and quantify CAEV in the viral or proviral form.

We designed a real time PCR protocol by using a primer couple flanking the env gene region representative for all CAEV sequences deposited in the GeneBank but containing many mismatch regions, in comparison with the Visna Maedi (MVV) isolate. With MVV env sequences, simulation analysis in silico by Hyther and mfold servers showed an increase in Gibbs energy (delta G), with a subsequent $\mathrm{Tm}$ decrement positioned from 7 to $50{ }^{\circ} \mathrm{C}$ for upper and lower primers respectively (Fig. 1). This observation was confirmed by a reconstruction experiment using a Visna maedi strain (It-651) as a DNA/RNA direct template for PCR real time or in experimentally infected sheep; these results suggest an absence of false CAEV positive results with samples containing MVV, demonstrating the optimal specificity of this molecular approach.

In this work we used an intercaling dye as a fluorescent probe (Sybr Green I). This procedure required a melting curve at the end of the amplification cycle to determine if the product is pure (amplicon only) or if there are non specific products like primer-dimers [41]. In our experiment, shown in Fig. (2), melting curves are localized on the graph in two distinct areas: (i) a $78^{\circ} \mathrm{C}$ peak region due to primer dimer products in negative samples (such as MVV positive samples), (ii) a $83^{\circ} \mathrm{C}$ peak region in positive CAEV samples; for this reason we positioned the fluorescence detention point at $80^{\circ} \mathrm{C}$ when the aspecific product signal is the lowest (for PCR and RT PCR), thereby avoiding specificity errors due to inappropriate fluorescence signals (Fig. 2).

By using a synthetic env gene fragment reproducing the PCR amplicon, this real time PCR showed a $5 \log$ linearity range, from $10^{2}$ to $10^{7}$ env fragments/PCR with a regression factor $\left(R^{2}\right)$ of 0.98 . Viral enumeration using the present procedure in clinical or laboratory samples (such as virus or provirus) could be useful for viraemia or proviral evaluation during anti-CAEV prophylactic measures or in laboratory experiments (such as cell culture infection). A comparative evaluation between serological and molecular procedures is shown by experimental infections and by biological samples recruited in subjects coming from infected areas.

First of all, experimental infections suggested a complete absence of fluorescence signals in samples recruited in sheep infected with MVV, despite the fact that a mean of $10^{3}$ proviral molecules PCR is detectable in CAEV infected sheep at 15 day PI, a correspective serological positive signal 
is detected around 40-60 day PI, this datum suggests that with this real time PCR we could "gain a time" of around 2545 days in diagnostic procedures, which (as discussed above) could be useful in an early prophylactic anti CAEV procedure. CAEV RNA was not detectable in these sheep until 71 days PI; this result could be due to low viraemia during this period. In clinical samples, only 7 Alpine goats were CAEV RNA positive, and their simultaneous positivity for CAEV DNA could indicate a very old infection (Table 2). All symptomatic goats (5 subjects) resulted proviral real time PCR positive (Table 1). The prognostic effect of this molecular approach on diagnosis for CAE is represented by Sardinian goats monitored serologically by the AGID procedure and the Alpine type monitored by Elisa. Two serologically negative samples resulted PCR positive (Tables 1 and 2), these subjects could be in a "window period". However some discrepancies were revealed in these specimens, i.e. sample 396 (Table 2) and A02 and K133 where serological positivity did not correspond to the molecular signal This could be due to different causes: (I) specificity mistakes with serological methods, (ii) PCR sensitivity mistakes (target $<10^{2}$ env/PCR or PCR inhibitors, in this case an internal amplification control (i.e. on $18 \mathrm{~S}$ rRNA gene) could be useful. The blood for proviral detection represented the best procedure in laboratory diagnosis for CAEV infection in goats/sheep.

In conclusion, we tested and validated the feasibility of a real time PCR such as PCR or RT PCR as a method for the detection and simultaneous quantisation of Caprine ArthritisEncephalitis Virus in naturally-infected goats or in experimentally infected sheep. This method showed a good sensitivity $\left(10^{2}\right.$ env fragment/PCR) and a good specificity $(100 \%)$ when this protocol was applied in experimentally infected subjects or goats with a clinical diagnosis of Caprine Arthritis-Encephalitis (CAE).

\section{ACKNOWLEDGEMENTS}

This work was supported by the Italian Ministry of Health, Ricerca Finalizzata, art-12 bis D.L.229/99, (DIAGNOVA).

\section{CONFLICT OF INTEREST}

The authors declares that they have no financial/commercial conflicts of interest.

\section{REFERENCES}

[1] Reina R, Mora MI, Glaria I, et al. Molecular characterization and phylogenetic study of Maedi Visna and Caprine Arthritis Encephalitis viral sequences in sheep and goats from Spain. Virus Res 2006; 121(2): 189-98.

[2] Pasick J. Maedi-visna virus and caprine arthritis-encephalitis virus: distinct species or quasispecies and its implications for laboratory diagnosis. Can J Vet Res 1998; 62(4): 241-4.

[3] Leitner G, Krifucks O, Weisblit L, Lavi Y, Bernstein S, Merin U. The effect of caprine arthritis encephalitis virus infection on production in goats. Vet J 2010; 183(3): 328-31.

[4] Bandeira DA, de Castro RS, Azevedo EO, de Souza Seixas Melo L, de Melo CB. Seroprevalence of caprine arthritis-encephalitis virus in goats in the Cariri region, Paraiba state, Brazil. Vet J 2009; 180(3): 399-401.

[5] Gufler H, Baumgartner W. Overview of herd and CAEV status in dwarf goats in South Tyrol, Italy. Vet Q 2007; 29(2): 68-70.

[6] Daltabuit Test M, de la Concha-Bermejillo A, Espinosa LE, Loza Rubio E, Aguilar Setien A. Isolation of caprine arthritis encephalitis virus from goats in Mexico. Can J Vet Res 1999; 63(3): 212-5.

[7] Greenwood PL, North RN, Kirkland PD. Prevalence, spread and control of caprine arthritis-encephalitis virus in dairy goat herds in New South Wales. Aust Vet J 1995; 72(9): 341-5.

[8] Konishi M, Tsuduku S, Haritani M, et al. An epidemic of caprine arthritis encephalitis in Japan: isolation of the virus. J Vet Med Sci 2004; 66(8): 911-7.

[9] Pisoni G, Bertoni G, Puricelli M, Maccalli M, Moroni P Demonstration of coinfection with and recombination by caprine arthritis-encephalitis virus and maedi-visna virus in naturally infected goats. J Virol 2007; 81(10): 4948-55.

[10] Pisoni G, Quasso A, Moroni P. Phylogenetic analysis of smallruminant lentivirus subtype B1 in mixed flocks: evidence for natural transmission from goats to sheep. Virology 2005; 339(2): 147-52.

[11] Saman E, Van Eynde G, Lujan L, et al. A new sensitive serological assay for detection of lentivirus infections in small ruminants. Clin Diagn Lab Immunol 1999; 6(5): 734-40.

[12] Johnson LK, Meyer AL, Zink MC. Detection of ovine lentivirus in seronegative sheep by in situ hybridization, PCR, and cocultivation with susceptible cells. Clin Immunol Immunopathol 1992; 65(3):254-60.

[13] Kaba J, Rola M, Materniak M, Kuzmak J, Nowicki M. Isolation and characterization of caprine arthritis encephalitis virus in goats from Poland. Pol J Vet Sci 2009; 12(2): 183-8.

[14] Ali Al Ahmad MZ, Fieni F, Pellerin JL, et al. Detection of viral genomes of caprine arthritis-encephalitis virus (CAEV) in semen and in genital tract tissues of male goat. Theriogenology 2008; 69(4): 473-80.

[15] Ali Al Ahmad MZ, Fieni F, Martignat L, et al. Proviral DNA of caprine arthritis encephalitis virus (CAEV) is detected in cumulus oophorus cells but not in oocytes from naturally infected goats. Theriogenology 2005; 64(7): 1656-66.

[16] Ganter M. [Clinical aspect of caprine arthritis and encephalitis]. Tierarztl Prax 1993; 21(6): 517-20.

[17] Burgu I, Akca Y, Alkan F, Ozkul A, Karaoglu T, Cabalar M. Antibody prevalence of caprine arthritis encephalitis virus (CAEV) in goats in Turkey. Dtsch Tierarztl Wochenschr 1994; 101(10): 390-1.

[18] Ali Al Ahmad MZ, Chebloune Y, Bouzar BA, et al. Lack of risk of transmission of caprine arthritis-encephalitis virus (CAEV) after an appropriate embryo transfer procedure. Theriogenology 2008; 69(4): 408-15.

[19] Reina R, Grego E, Profiti M, et al. Development of specific diagnostic test for small ruminant lentivirus genotype E. Vet Microbiol 2009; 138(3-4): 251-7.

[20] Lacerenza D, Giammarioli M, Grego E, et al. Antibody response in sheep experimentally infected with different small ruminant lentivirus genotypes. Vet Immunol Immunopathol 2006; 112(3-4): 264-71.

[21] Shah C, Boni J, Huder JB, et al. Phylogenetic analysis and reclassification of caprine and ovine lentiviruses based on 104 new isolates: evidence for regular sheep-to-goat transmission and worldwide propagation through livestock trade. Virology 2004; 319(1): 12-26.

[22] Bommarito S, Peyret N, SantaLucia J, Jr. Thermodynamic parameters for DNA sequences with dangling ends. Nucleic Acids Res 2000; 28(9): 1929-34.

[23] Orru G, Masia G, Romano L, Piras V, Coppola RC. Detection and quantitation of hepatitis $\mathrm{E}$ virus in human faeces by real-time quantitative PCR. J Virol Methods 2004; 118(2):77-82.

[24] Roux KH. Optimization and troubleshooting in PCR. Cold Spring Harb Protoc 2009; 2009(4): pdb ip66.

[25] Varga A, James D. Real-time RT-PCR and SYBR Green I melting curve analysis for the identification of Plum pox virus strains $\mathrm{C}$, EA, and W: effect of amplicon size, melt rate, and dye translocation. J Virol Methods 2006; 132(1-2): 146-53.

[26] Koenig M, Reynolds KS, Aldous W, Hickman M. Comparison of Light-Cycler PCR, enzyme immunoassay, and tissue culture for detection of herpes simplex virus. Diagn Microbiol Infect Dis 2001; 40(3): 107-10.

[27] Russo P. [Caprine arthritis-encephalitis virus (CAEV). Short review]. Ann Rech Vet 1984; 15(1): 3-6.

[28] Knowles DP Jr, Evermann JF, Shropshire C, et al. Evaluation of agar gel immunodiffusion serology using caprine and ovine 
lentiviral antigens for detection of antibody to caprine arthritisencephalitis virus. J Clin Microbiol 1994; 32(1): 243-5.

[29] Adams DS, Crawford TB, Banks KL, McGuire TC, Perryman LE. Immune responses of goats persistently infected with caprine arthritis-encephalitis virus. Infect Immun 1980; 28(2): 421-7.

[30] Crawford TB, Adams DS, Cheevers WP, Cork LC. Chronic arthritis in goats caused by a retrovirus. Science 1980; 207(4434): 997-9.

[31] Baba SS, Fotabe AI, Baba MM, Rimstad E. Preliminary survey for antibodies against caprine arthritis-encephalitis virus (CAEV) using recombinant GAG proteins: studies among small ruminant populations in north-eastern Nigeria. Small Rumin Res 2000; 37(12): $137-40$.

[32] Rowe JD, East NE. Risk factors for transmission and methods for control of caprine arthritis-encephalitis virus infection. Vet Clin North Am Food Anim Pract 1997; 13(1): 35-53.

[33] Lerondelle C, Godet M, Mornex JF. Infection of primary cultures of mammary epithelial cells by small ruminant lentiviruses. Vet Res 1999; 30(5): 467-74.

[34] Gil A, Rola M, Kuzmak J. Application of PCR technique in diagnosis of small ruminant lentivirus infection in sheep and goats. Pol J Vet Sci 2006; 9(4):213-7.
[35] Eltahir YM, Dovas CI, Papanastassopoulou M, et al. Development of a semi-nested PCR using degenerate primers for the generic detection of small ruminant lentivirus proviral DNA. J Virol Methods 2006; 135(2): 240-6.

[36] Wagter LH, Jansen A, Bleumink-Pluym NM, Lenstra JA, Houwers DJ. PCR detection of lentiviral GAG segment DNA in the white blood cells of sheep and goats. Vet Res Commun 1998; 22(5): 35562 .

[37] Leroux C, Lerondelle C, Chastang J, Mornex JF. RT-PCR detection of lentiviruses in milk or mammary secretions of sheep or goats from infected flocks. Vet Res 1997; 28(2): 115-21.

[38] Clavijo A, Thorsen J. Chemiluminescent detection of caprine arthritis encephalitis virus with a PCR-generated single stranded nonradiolabelled probe. Vet Microbiol 1995; 43(4): 295-305.

[39] Rimstad E, East NE, Torten M, Higgins J, DeRock E, Pedersen NC. Delayed seroconversion following naturally acquired caprine arthritis-encephalitis virus infection in goats. Am J Vet Res 1993; 54(11): 1858-62.

[40] Reddy PG, Sapp WJ, Heneine W. Detection of caprine arthritisencephalitis virus by polymerase chain reaction. J Clin Microbiol 1993; 31(11): 3042-3.

[41] Wilhelm J, Pingoud A. Real-time polymerase chain reaction. Chembiochem 2003; 4(11): 1120-8. 